\title{
A SEGUNDA GUERRA MUNDIAL, OS NIPO-GANADENSES E A PRIMEIRA FASE DO MOVIMENTO PELOS DIREITOS HUMANOS NO CANADÁ
}

Stephanie Bangarth'

Resumo: Este artigo estuda, no contexto da Segunda Guerra Mundial, as políticas segregacionistas do governo canadense com relação às populações de origem japonesa no Canadá, bem como as estratégias e alianças políticas desses grupos para evitar a desagregação de suas comunidades e a deportação dos seus membros. O estudo do caso dos nipo-canadenses ajuda a iluminar a emergência no Canadá de um movimento mais amplo de luta pelos direitos humanos.

Palavras-chave: Direitos Humanos; $2^{\mathrm{a}}$ Guerra Mundial; Nipo-Canadenses; Canadá; Século XX

Abstract: This paper studies the segregationist policies of the Canadian government with respect to the people of Japanese origin in Canada in the context of the Second World War. It also studies the strategies and political alliances of these groups to prevent the disintegration of their communities and the deportation of its members. The case study of Japanese-Canadians helps to illuminate the emergence in Canada of a broader movement to fight for human rights.

Key-Words: Human Rights; World War II; Japanese-Canadians; Canada; XXth Century

No discurso de Henry Wilcoxon ${ }^{2}$ que ficou famoso, o Vigário que ele interpretava no filme britânico sobre a Segunda Guerra, "Mrs. Miniver”, proclamava, “[...] esta não é apenas uma guerra de soldados em uniformes. É uma guerra do povo, de todo o povo, e deve ser lutada não apenas no campo de batalha, mas nas cidades e nos povoados, nas fábricas e nas fazendas, no lar e no coração de cada homem, mulher e criança que ama a liberdade!"3 A poderosa "experiência nacional” que a guerra trazia à tona em cada uma das nações que dela participavam resultou em mudanças significativas, tanto positivas quanto negativas, nas

\footnotetext{
I Professora do King's University College, University of Western Ontario, Canadá. Este artigo foi originalmente apresentado no Seminário Internacional "Relações Raciais, Direito e História" na Universidade Federal de Santa Catarina, em 17 de setembro de 2007. Tradução: Henrique Espada Lima e Beatriz Gallotti Mamigonian.
} 
esferas econômica, social, cultural e política no Canadá. O período da Segunda Guerra Mundial anunciou o começo de uma batalha articulada pelo fim da perseguição racial e pelo reconhecimento dos direitos humanos de todos os cidadãos do Canadá. Apesar da batalha por direitos certamente não ter envolvido "cada homem, mulher e criança”, alguns grupos de canadenses que incluíam aqueles historicamente afetados pelo preconceito racial incitaram a ira dos seus concidadãos e confrontaram vários níveis do governo para que fossem propostas as mudanças nas políticas públicas que muitos canadenses exigiam. A natureza dessas exigências era baseada em uma série de mudanças importantes que ocorriam naqueles tempos.

Uma das transformações mais significativas que ocorreu no curso da Segunda Guerra foi a crescente consciência dos canadenses a respeito dos seus direitos. Grupos que defendiam as liberdades civis expandiram suas áreas de preocupação de modo a incluir não apenas os direitos liberais (isto é, o direito de livre expressão, de assistência legal, direitos de propriedade) mas também a atenção aos direitos igualitários (o direito à igual proteção da lei). Em termos discursivos, a linguagem dos direitos passou de uma ênfase nas "liberdades britânicas" para um foco sobre os "direitos humanos". Ativistas dos direitos também se tornaram mais inclusivos, reconhecendo a necessidade de formar alianças com outros grupos interessados, que muitas vezes incluíam minorias raciais, religiosas e étnicas.

Um caso em especial demonstra de modo claro a preocupação crescente dos canadenses com o racismo, os direitos e a igualdade durante a Segunda Guerra e no período do imediato pós-guerra: a campanha pelo "Comitê Cooperativo sobre os Nipo-Canadenses" (Co-operative Committee on Japanese Canadians CCJC) para impedir expatriação de milhares de canadenses de ascendência japonesa. A campanha apelou para o discurso emergente dos direitos humanos e foi notável pela participação de nipo-canadenses em papéis de liderança. Apesar do seu mandato prático limitado, as atividades do CCJC demonstraram como um grande número de organizações, incluindo as principais denominações religiosas da época e os sindicatos, políticos e partidos políticos, alguns jornais e periódicos liberais diários e semanais (como o Star de Toronto, o Free Press de Winnipeg, o Canadian Forum e a revista Saturday Night), assim como indivíduos proeminentes e membros das comunidades afetadas podiam transcender a política e se unir para defender os direitos humanos de um grupo étnico minoritário. Destacase que os nipo-canadenses não aceitaram passivamente seu "destino”, nem se submeteram a políticas governamentais racistas e opressivas; eles foram ativos em sua própria defesa, indicando a politização crescente dos grupos minoritários no período do pós-guerra. Ao escapar da imagem dos nipo-canadenses como vítimas das políticas governamentais, este artigo prefere enfocar "aquilo que as 
pessoas fizeram, em vez de o que foi feito a elas.” ${ }^{4}$ O CCJC uniu esses grupos distintos e seus esforços podem ser vistos como uma progressão de conquistas de objetivos de curto prazo, perseguidas por um grupo de canadenses funcionando coletivamente como membros de uma pioneira comunidade de luta pelos direitos humanos.

Pesquisas acadêmicas recentes apontam para as políticas públicas do governo federal de encarceramento e deportação de nipo-canadenses como tendo tido um impacto sobre o "surgimento do idealismo igualitário" que teve lugar no Canadá do pós-guerra. ${ }^{56}$ De fato, a campanha para obter justiça para as pessoas de ascendência japonesa, especialmente com respeito à deportação e a expatriação, representou o primeiro e mais significativo envolvimento canadense com o discurso dos direitos humanos. A atenção daqueles que advogavam a causa e suas estratégias de influência foram além das liberdades civis e do apelo ao respeito às "tradicionais liberdades britânicas" e na direção de uma retórica que incluía as ideias recém-articuladas de direitos humanos, tais como haviam sido expressas na Carta Atlântica e, mais tarde, na Carta das Nações Unidas. Ainda que a falta de um Bill of Rights em estilo americano tenha levado os defensores da causa a olharem para a Carta Atlântica e a Carta das Nações Unidas para dar aos seus argumentos substância e significado, isso não sugere, entretanto, que a experiência canadense tenha de algum modo proclamado algo de mais louvável; na verdade, os canadenses fizeram o melhor de uma situação difícil.

As implicações contrastantes da "raça” e da etnicidade na Segunda Guerra nunca foram tão claramente reveladas quanto no caso de um grupo que se encaixava nas duas categorias: as pessoas de ascendência japonesa residentes no Canadá. Apesar das várias restrições voltadas a muitos grupos minoritários, foram as dificuldades enfrentadas pelos nipo-canadenses no tempo da guerra que provocaram o interesse dos defensores da causa. Canadenses de ascendência japonesa, tanto nascidos no país quanto naturalizados, sofreram um grande número de injustiças baseadas na "raça” desde que chegaram, no fim do século dezenove. Entretanto, as políticas adotadas durante a Segunda Guerra foram extremas e colocaram em cheque as crenças de muitos canadenses a respeito de suas próprias instituições democráticas.

O reassentamento dos nipo-canadenses não foi uma decisão tomada do dia para a noite, nem aconteceu sem uma certa confusão, como indicou uma testemunha em suas memórias daquela provação: "O governo federal está perdido, sem saber exatamente como lidar conosco, japoneses do Canadá. As ordens mudam de um dia para o outro, sem um princípio que as guie"7. O processo tomou a forma de uma série crescente de medidas ad hoc tomadas pelo governo liberal de Mackenzie King logo depois do ataque de Pearl Harbor. Começou pelo registro de todos os 
japoneses na Colúmbia Britânica, seguido pela prisão e o internamento de trinta e oito japoneses tidos como perigosos para a segurança nacional. Na primavera e no verão de 1941, todas as pessoas de origem japonesa foram obrigadas a submeterse ao processo de registro e a carregar seus cartões de registro todo o tempo. Em dezembro de 1941, 1.200 barcos de pesca de propriedade de japoneses foram retidos e os movimentos de pessoas de origem japonesa passaram a ser monitorados e restringidos pela polícia (Royal Canadian Mounted Police, RCMP). Em janeiro de 1942, um Comitê Permanente sobre os orientais, instância federal, ordenou o "internamento" de todos os nipo-canadenses do sexo masculino em idade militar; esse foi o terceiro e último passo nessa fase inicial da política de reassentamento. Três dias depois aconteceu uma conferência de políticos federais e provinciais, oficiais militares e policiais para discutir a situação na costa oeste. Quando as medidas parciais não foram suficientes para calar as vozes anti-japonesas que ecoavam na Colúmbia Britânica e por todo o Canadá, King anunciou, em 24 de fevereiro, uma política de remoção total de todos os nikkei, sem distinção de status de estrangeiro ou cidadão, da faixa protegida de 100 milhas na costa oeste, por medida de necessidade militar. ${ }^{8}$ Assim se deu o terceiro passo dessa fase inicial. Não era uma ideia original. Militantes anti-japoneses na costa oeste vinham advogando algum tipo de medida semelhante há alguns anos. A Colúmbia Britânica, como um especialista notou, era "a criança problemática do Canadá no que diz respeito à legislação discriminatória”.

Ainda que a política de remoção trouxesse a inconfundível marca da opinião pública da costa oeste, o governo não pode ser completamente absolvido da culpa. King e os membros do seu governo eram produtos do seu tempo e certamente acreditavam na ideologia racial corrente. Ainda assim, a medida não respondia a uma necessidade militar, e as autoridades militares canadenses e a RCMP discordavam fortemente do governo de King sobre a necessidade da remoção. A população japonesa da Colúmbia Britânica compunha meros 2,7\% do total, mas a questão é que ela se concentrava de modo intenso, criando "guetos étnicos" nos centros urbanos da província. Mas nem toda a concentração japonesa se dava em áreas urbanas, entretanto. Agrupamentos significativos podiam ser encontrados na aldeia pesqueira de Steveston e em vários lugares do Fraser Valley. No fim das contas, a política canadense de reassentamento envolveu mais de 21.000 pessoas de ascendência japonesa, representando mais de $90 \%$ da população japonesa no Canadá. Desses, quase 4.000 seriam “repatriados” para o Japão ou de modo mais acurado para o caso de cidadãos canadenses de ascendência nipônica - expatriados. Dos 17.000 remanescentes, apenas cerca de 4.000 voltaram à costa oeste, enquanto os remanescentes re-estabeleceram-se a leste das Montanhas Rochosas ${ }^{10}$. 
Hoje a opinião corrente é que a política de encarceramento foi uma violação dos valores democrático-liberais, mas virtualmente todos os liberais em 1942 a encararam como um mal necessário, justificável em termos de segurança nacional, assim como de defesa contra a possibilidade de ataques populares violentos anti-japoneses. Aqueles membros da pioneira comunidade dos direitos humanos que poderiam sob outras condições ter protestado contra a política governamental, na verdade a apoiaram. Mesmo o Cooperative Commonwealth Federation $(\mathrm{CCF})^{11}$, que por muito tempo defendeu direitos iguais para grupos étnicos minoritários, não estava disposto a criticar o governo, e as igrejas estavam igualmente ao lado do governo.

Em fevereiro de 1945, o governo federal forneceu mais detalhes sobre o futuro dos nipo-canadenses. Diferente do governo dos Estados Unidos, que havia removido recentemente todos os controles sobre os nipo-americanos, o Canadá anunciou um programa de "repatriação voluntária" através do qual os nipocanadenses podiam optar entre mudar-se para a região ao leste da Montanhas Rochosas ou ser enviado ao Japão. Até maio daquele ano, mais de 6.000 formulários de repatriação haviam sido preenchidos, em nome de mais de 10.000 homens, mulheres e crianças, em sua maioria cidadãos canadenses e representando mais de $40 \%$ da população nipo-canadense.

Foi neste ponto que o Comitê Co-operativo sobre os Nipo-Canadenses desempenhou um importante papel nacional. Quando os nipo-canadenses começaram a chegar em Toronto, eles foram ajudados por um conjunto de voluntários, vários dos quais haviam sido missionários no Japão e que representavam a Associação Cristã Feminina (Young Women’s Christian Association - YWCA), assim como as mulheres das sociedades missionárias da United Church of Canada e da Igreja Anglicana. Integração e assimilação eram os objetivos principais deste grupo pioneiro. E, de fato, esse foco limitado era evidente no seu nome original: o Comitê Co-operativo sobre as Chegadas de Nipo-Canadenses em Toronto. Esse grupo foi formado em junho de 1943 e era composto majoritariamente por membros do sexo feminino da United Church e da Igreja Anglicana de Toronto. Era uma organização puramente filantrópica, sem intenções políticas. Já em 1944 ele havia aceito a filiação de outros grupos e começava a engajar-se na pressão política. Nessa ocasião já havia mudado seu nome para Comitê Co-operativo para os Nipo-Canadenses (Co-operative Committee for Japanese Canadians CCJC), mas não estava ainda organizado para protestar contra as legislações federais de cassação de direitos daquele tempo. Mas em 1946, o CCJC já estava suficientemente organizado para lançar um protesto vigoroso contra a política de deportação do governo. Foi quando Andrew Brewin foi contratado como consultor legal pelo Comitê. Esta mudança de foco foi dada pela decisão do governo 
liberal de Mackenzie King de deportar todas as pessoas de ascendência japonesa que desejassem a "repatriação" para o Japão, ou para aqueles que não quisessem ser reassentados nas províncias do leste canadense. O CCJC questionou legalmente a medida, recurso que acabou sendo julgado pela Suprema Corte do Canadá e, depois, em apelação, pelo Conselho do Rei (Privy Council) ${ }^{12}$.

O presidente desse novo corpo era o Reverendo James Finlay, um ministro franco, direto e controverso da United Church, com fortes antecedentes pacifistas e um longo comprometimento com a causa dos Nipo-Canadenses. Quem mais participava do CCJC? Entre eles estavam membros de outros grupos minoritários, especialmente da comunidade nipo-canadense, assim como da comunidade judaica, representada pelo Congresso Judeu Canadense (CJC). Houve, entretanto, pouca colaboração de outros grupos minoritários que trabalhavam em isolamento, provavelmente resultado de sua própria hostilidade aos nipo-canadenses; os povos aborígenes e os chineses viam-nos frequentemente como competidores no plano econômico. No caso da comunidade negra do Canadá, entretanto, isso se deu provavelmente pela sua politização rudimentar, uma vez que ainda não existia nenhuma associação dos afro-canadenses. É igualmente importante reconhecer que "brancos liberais” não eram os únicos envolvidos em um papel de defesa dos nipo-canadenses. Pessoas de ascendência japonesa eram ativas em defender seus próprios direitos e trabalharam muito próximas do CCJC. Os japoneses levaram seu próprio impulso para a campanha, mas foi, inquestionavalmente, através das representações dos seus camaradas brancos que a justiça foi obtida. As crenças raciais em vigor na época impediram os japoneses de buscarem a igualdade sozinhos. Assim, as duas dinâmicas tiveram que se articular para conseguir um resultado efetivo.

Na medida que o CCJC deixava de ser apenas um comitê de boas-vindas e passava a preocupar-se com as liberdades civis, o conjunto dos seus membros começou a refletir essas mudanças. A lista de membros incluía cerca de cinquenta e seis nomes, muitos dos quais podem ser identificados na elite acadêmica, libertária e literária canadense. Membros de vários sindicatos - ironicamente, alguns dos mesmos sindicatos que argumentaram contra a imigração japonesa no início do século XX - também eram membros do CCJC, e da mesma forma com algumas organizações de mulheres. Mas a maior parte dos membros era ligada a instituições religiosas, em especial à United Church e à Igreja Anglicana, que viram seu papel como defensoras da causa como uma extensão de seu trabalho missionário dentro e fora do país entre os povos “orientais" que vinha sendo feito desde a metade do século XIX. O CCJC também se transformou no sentido estrutural, na medida em que se formaram grupos locais pelo Canadá, como em London, Ontário; Winnipeg, Manitoba e em vários lugares de Alberta, para localizar os esforços do grupo nacional baseado em Toronto ${ }^{13}$. 
Já em 1944, entretanto, as lideranças das igrejas cristãs canadenses começaram a ter dúvidas sobre a direção dos planos do governo federal com respeito aos nipo-canadenses. Ainda que a dispersão (especialmente a dispersão voluntária) fosse amplamente aceitável, a perda de direitos e a deportação em massa não eram, e alguns líderes de igrejas cristãs expressaram publicamente sua oposição. Seu ativismo crescente correspondia à opinião pública canadense em geral. De acordo com a pesquisa do Instituto Canadense de Opinião Pública, publicada em fevereiro de 1944, apenas 33\% dos canadenses apoiava a ideia de deportação. Esses resultados estavam em claro contraste com a pesquisa contratada em dezembro de 1943, que indicava que pouco mais de 50\% dos canadenses, incluindo uma maioria significativa dos habitantes da Colúmbia Britânica, eram favoráveis à deportação ${ }^{14}$.

Nesse ponto, a resposta das igrejas cristãs canadenses começou a representar a consciência crescente dos direitos humanos como uma questão digna de importância na sociedade canadense. Muitos membros proeminentes das igrejas começaram a se dar conta que as instituições religiosas tinham uma obrigação de agir quando o Estado impunha medidas opressivas. A Irmandade para uma Ordem Social Cristã (Fellowship for a Christian Social Order (FCSO), um grupo formado principalmente por radicais em questões sociais pertencentes à United Church, por exemplo, representou essa ideia da "religião como algo que se preocupa com a comunidade e a democracia" e que "a vida religiosa deveria [...] desembocar também em atividades sócio-políticas” ${ }^{15}$. Outros grupos, como o Movimento Cristão dos Estudantes (SCM) e a Irmandade da Reconciliação (FOR), que também se interessaram pelo tratamento dispensado aos nipo-canadenses, abordaram a questão da perspectiva de um cristianismo radical, um sistema de crenças enraizado no Evangelho Social. É interessante notar que estas organização estavam entre as primeiras a apoiar o CCJC. Richard Allen notou que a "convicção de que o cristianismo exigia um comprometimento apaixonado com o envolvimento social” era uma doutrina central do Evangelho Social e um padrão importante a guiar seus partidários. Ainda que o movimento do Evangelho Social tenha começado a declinar nos anos 1920, alguns membros da United Church, em particular, continuaram a ser influenciados pelas ideias do movimento. O Cristianismo Radical adotava essencialmente uma visão de mundo igualitária que levava aqueles que possuíam essa crença a apoiar os direitos humanos. A convicção de que todas as pessoas são iguais perante o Senhor levou à perspectiva de que as minorias no Canadá deveriam possuir os mesmos direitos e privilégios dos outros canadenses ${ }^{16}$.

As igrejas cristãs canadenses começaram suas primeiras campanhas públicas e esforços de convencimento com a questão da cassasão de direitos dos 
nipo-canadenses. Funcionários do Comitê para Missões Estrangeiras da United Church do Canadá enviaram cartas aos Membros do Parlamento e ao Primeiro Ministro King, opondo-se ao projeto ${ }^{\circ} 135$ (artigo 5), que propunha cassar os direitos de "todas as pessoas cuja origem racial é a mesma de um país em guerra com o Canadá" ${ }^{17}$. Entretanto, as palavras foram ligeiramente distorcidas de modo a ter o efeito de cassar os direitos dos cidadãos canadenses de ascendência japonesa que viviam a leste das Montanhas Rochosas. Os oponentes do projeto de lei, por outro lado, argumentaram que aqueles

que nasceram neste país não são mais responsáveis por aquilo que os militaristas dos países de sua origem racial fizeram ou estão fazendo do que os cidadãos canadenses de qualquer outra origem racial. Por que, portanto, discriminá-los apenas a eles e não aos canadenses cuja ascendência seja alemã, italiana, finlandesa, húngara, romena ou búlgara?

As cartas também faziam referência à Carta Atlântica e às obrigações do Canadá em manter seus compromissos internacionais com a proibição da discriminação racial. A FCSO também protestou contra o projeto $n^{\circ} 135$ como parte do seu Programa de Igualdade Racial, argumentando que os cidadãos nipo-canadenses mereciam os mesmos direitos legais e liberdades civis do que os outros súditos britânicos ${ }^{18}$. Além disso, líderes e membros individuais das igrejas cristãs enviaram várias cartas de protesto ao governo federal sobre o mesmo assunto. Durante os meses de junho e julho de 1944, de fato, cartas de aproximadamente sessenta pessoas e organizações foram recebidas e registradas pelo Gabinete do Primeiro Ministro. Entre estas se incluíam cartas de ramos da YMCA (Associação Cristã de Moços), dos grupos de mulheres (Women's Auxiliaries) da United Church e da Igreja Anglicana, além de alguns líderes representando a United Church e a Igreja Anglicana ${ }^{19}$.

Muito antes de Mackenzie King propor as três Orders-in-Council ${ }^{20}$ (P.C. 7355, 7356, 7357) que permitiram ao governo deportar pessoas de ascendência japonesa do Canadá, incluindo aquelas nascidas no país, as igrejas cristãs e os grupos religiosos aliados expressaram suas preocupações sobre a ideia da deportação em massa. Essas não foram apenas declarações piedosas ou oportunistas feitas após a constatação que a derrota japonesa na guerra estava garantida, como alguns estudiosos sugeriram ${ }^{21}$. Diferente disso, elas representam a visão das igrejas cristãs de que o único caminho humanitário e construtivo através do qual enfrentar o "problema” dos nipo-canadenses era a dispersão geográfica. Além de ser "falso, cruel e ir contra os princípios britânicos, e sobretudo cristãos”22, a deportação contradizia o próprio comprometimento das igrejas cristãs com o princípio da dispersão. 
As publicações ligadas às igrejas cristãs eram o fórum principal através do qual as autoridades religiosas podiam divulgar sua oposição. Os censores do governo tiveram bastante trabalho a partir de 1944 ao lidar com a terminologia usada, bem como os pontos de vista sustentados, por várias dessas revistas. Em particular, The Canadian Churchman, uma revista semanal anglicana publicada em Toronto, assim como revistas escritas pelos franciscanos e jesuítas, foram identificadas por F. Charpentier, Censor-Chefe de Publicações, como sendo especialmente problemáticas a esse respeito ${ }^{23}$.

Em maio de 1944, o Comitê Consultivo de Vancouver (Vancouver Consultative Committee - VCC) somou sua voz à crescente oposição a qualquer proposta de deportação. O grupo acabou tornando-se uma organização significativa em defesa das liberdades civis na luta contra a deportação/expatriação. Em muitos aspectos, o VCC era a "ala Ocidental" do CCJC, mantendo as pessoas de Toronto informadas sobre os movimentos que aconteciam na Costa Oeste. O VCC não questionou a natureza da política de encarceramento, mas focalizou, por outro lado, a questão do justo tratamento de todos os nipo-canadenses e insistiu junto ao governo federal para que formulasse políticas que visassem diminuir o sentimento anti-asiático.

Em sua carta ao Primeiro Ministro, o presidente do VCC, Dr. Norman F. Black escreveu:

A proposta de que todas as pessoas de extração japonesa deveriam ser forçosamente excluídas deste Domínio nos parece deturpada e absurda. Nós temos dificuldade em entender como alguém pode apoiar tal sugestão a menos que, consciente ou inconscientemente, tenha se rendido à atitude racial característica do Nazismo [...] Nós sentimos que falar em ‘repatriação’ é um abuso de linguagem e que o exílio forçado destes 16.261 cidadãos canadenses seria um ato de tirania e estupidez indefensável [...] Finalmente [...] a proposta de expulsão iria realizar uma violência à consciência de um amplo setor do povo canadense. ${ }^{24}$

Certamente, a "consciência” a que se referia o VCC em sua carta ao Primeiro Ministro King se referia à aceitação crescente do conceito de "direitos humanos” que estava ganhando reconhecimento, tanto internacionalmente quanto no próprio Canadá. Esta carta também era assinada por líderes das denominações anglicana, unificada, batista e católica romana em Vancouver.

As igrejas cristãs comprometeram "amplas somas" de dinheiro para o financiamento do caso em um plano jurídico e o Movimento dos Estudantes Cristãos levantou fundos e "manteve a questão acesa nos círculos universitários e nas comunidades locais" 25 . Por exemplo, num apelo apaixonado enviado a todos os grupos de jovens cristãos, os membros foram chamados a 
parar e pensar o que isso [a deportação] significa em termos do fracasso da democracia canadense, a impotência da Igreja Cristã, a degradação da posição do Canadá entre as nações, as sementes da Terceira Guerra Mundial e o custo em sofrimento humano para milhares de co-cidadãos canadenses[...] Este é um desafio à consciência da comunidade cristã para agir em defesa dos direitos humanos fundamentais. ${ }^{26}$

Em 18 de janeiro de 1946, uma delegação do Conselho Canadense de Igrejas visitou o Primeiro Ministro para lhe expressar sua desaprovação com relação às ações governamentais ${ }^{27}$.

Os partidos políticos, a mídia e os moderados ligados ao governo também foram influentes na defesa dos direitos dos nipo-canadenses. O CCF, por exemplo, foi o único partido político a denunciar abertamente na Câmara dos Comuns as políticas de reassentamento e deportação desde o princípio. David Croll, membro do parlamento pelo partido liberal nunca rompeu com o governo na Câmara dos Comuns, mas em um discurso em um fórum do CCJC na Universidade de Toronto em fevereiro de 1946, argumentou que as políticas do governo violavam os princípios da Carta das Nações Unidas. Croll também acompanhou membros do CCJC e seus apoiadores em sua audiência com o Primeiro Ministro. Os senadores Arthur Roebuck e Cairine Wilson também apoiaram as ações do CCJC, discursando duramente contra a política de deportação em um comício organizado pelo CCJC, entre outros grupos, no início de janeiro de $1946^{28}$.

Defensores de longa data das pessoas de ascendência japonesa no Canadá, Angus MacInnis do CCF, membro do Parlamento por Vancouver Oriental e sua mulher, Grace, integrante da legislatura provincial da Colúmbia Britânica e também membro do CCF, escreviam frequentemente sobre questões ligadas à igualdade de direitos. Certamente, nenhum deles desviava-se da perspectiva liberal que considerava o reassentamento para leste das Montanhas Rochosas um resultado positivo do encarceramento. Entretanto, um artigo que Angus MacInnis publicou em 1943 no semanário Maclean's é interessante por sua consciência incipiente dos conceitos de direitos humanos e da cidadania canadense. Sua conclusão, em particular, sugeria princípios igualitários:

Para concluir, eu defendo que se garanta àqueles de origem japonesa no Canadá todos os direitos e privilégios que eu tenho, tendo como base a única consideração de que são todos seres humanos. Negar a eles mesmo que uma letra dos direitos e privilégios gozados por [...] indivíduos da raça a qual eu pertenço seria uma negação da fraternidade dos homens; uma negação a humanos como eu de direitos e privilégios que eu gozo pela única razão de que a minha raça chegou aqui primeiro. ${ }^{29}$ 
Enquanto a mídia era em geral unânime no seu apoio ao reassentamento no começo da guerra, na medida em que as vitórias aliadas no Extremo Oriente passaram a ser mais numerosas, essa unanimidade começou a dissolver-se. Isso começou com os jornais tradicionalmente liberais, como o Free Press de Winnipeg e o Star de Toronto, assim como revistas de notícias semanais, como a Saturday Night. Gradualmente, cartas ao editor e editoriais opondo-se à deportação de cidadãos canadenses de ascendência japonesa puderam ser encontrados em outros periódicos por todo o país. Somando-se à distribuição de panfletos, a pregação diária em favor dos nipo-canadenses e as numerosas campanhas de petição levadas adiante por organizações religiosas, a resposta da mídia representou uma oposição efetiva ao rígido racismo anti-japonês corrente.

Enquanto os defensores das pessoas de ascendência japonesa eram, em sua maior parte, de um certo "tipo", isto é, usualmente brancos, do sexo masculino, religiosos e/ou profissionais liberais, as pessoas de ascendência japonesa não estavam passivas durante o movimento que defendia seus direitos. De fato, os nipo-canadenses contribuíram para o discurso dos direitos humanos quando foi esse articulado no período do imediato pós-guerra.

É certo que se pode argumentar que os grupos nipo-canadenses (dos quais havia muitos; nenhuma voz nacional unificada surgiu até a formação da NJCCA no final da década de 1940) focaram as estratégias conservadoras e acomodacionistas de dispersão, assimilação e patriotismo. E, de fato, essas respostas ecoavam os sentimentos dos defensores não-nipo-canadenses da causa, em sua abordagem das políticas de remoção. No fim das contas, as políticas de remoção e a dispersão associada a elas eram "justificadas”, tanto para os japoneses quanto para os não japoneses, por terem consequências benéficas; em especial, essa dispersão iria resultar em uma imersão maior das pessoas de ascendência japonesa dentro do conjunto da sociedade canadense.

A dispersão em direção à costa leste resultou na formação de outros grupos em torno dos nissei, especialmente o Comitê Nipo-Canadense pela Democracia (Japanese Canadian Committee for Democracy -JCCD). O JCCD nasceu de dois sub-comitês do Comitê Co-operativo sobre a Chegadas dos NipoCanadenses em Toronto (Co-operative Committee on Japanese Canadian Arrivals to Toronto - CCJC-AT), que foram organizados em 1943, um período no qual a comunidade nipo-canadense estava desorganizada. Como o propósito inicial do CCJC-AT, os Comitês de Homens e Mulheres Nissei tentavam reduzir o preconceito e aumentar as oportunidades para os nipo-canadenses em Toronto. Nesse ponto, o CCJC-AT era apolítico e funcionava primordialmente como uma associação benevolente. Os Comitês de Homens e Mulheres Nissei também se esforçaram por reportar ao CCJC-AT questões referentes ao bem estar e as 
necessidades dos nipo-canadenses naquela cidade. O grau de cooperação entre a comunidade nipo-canadense de Toronto e os membros liberais brancos, de classe média e politicamente ativos do CCJC-AT evoluiu nos primeiros anos da Segunda Guerra Mundial. Tanto os membros japoneses quanto os não-japoneses do CCJCAT trabalharam juntos para estudar as "orders-in-council” voltadas para os nipocanadenses e para estabelecer a moradia cooperativa nissei, um albergue com acomodação para vinte nipo-canadenses do sexo masculino ${ }^{30}$.

A relação de cooperação que existiu entre os nipo-canadenses e os membros brancos do CCJC foi formalmente reconhecida em um relatório submetido ao CCJC pelos sub-comitês nipo-canadenses em $1^{\circ}$ de novembro de 1943. Nos primeiros anos do Comitê Co-Operativo, seus membros nipo-canadenses foram instrumentais para o estabelecimento das direções a serem tomadas pelas atividades de apoio à causa e para ensinar aos membros do CCJC em geral sobre os sofrimentos específicos da comunidade nipo-canadense. Membros dos Sub-Comitês de Homens e Mulheres Nissei do CCJC sentiram, entretanto, que outras ações além dos objetivos práticos de fornecer alojamento e emprego eram necessárias. Muitos estavam procurando tornar-se politicamente organizados e assim, em 1944, criaram o JCCD. Sua criação coincidiu com a decisão dos membros do CCJC em tornarem-se mais politicamente ativos em favor dos bem-estar dos nipo-canadenses. Quando a Câmara dos Comuns aprovou o projeto 135, que de fato estenderia para o nível federal a perda de direitos que já existia nas províncias como a Colúmbia Britânica, inteiramente baseada em fundamentos raciais, o CCJC viu isso como uma oportunidade para demonstrar suas recém descobertas ambições políticas. Seu impacto foi emudecido, entretanto, na medida em que apenas membros individuais conseguiram apresentar sua oposição escrevendo cartas de protesto ao governo ${ }^{31}$. Ainda assim, representantes do JCCD viajaram a Ottawa para apresentar uma declaração ao governo, marcando sua oposição à lei a partir das sete posições seguintes:

1. À emenda proposta não foi dada a oportunidade adequada de discussão na Câmara dos Comuns.

2. A emenda proposta é uma abdicação injustificada do poder parlamentar da federação (Dominion) e é inconstitucional.

3. A emenda proposta é um precedente perigoso, que não leva ao bem-estar do Canadá.

4. A emenda proposta é uma privação injustificada dos direitos de cidadãos canadenses.

5. A emenda proposta é contrária à política governamental expressa com respeito à dispersão geográfica dos pessoas de raça japonesa no Canadá.

6. A emenda proposta é contrária aos desejos na maior parte da opinião pública do Canadá. 
7. A emenda proposta é contrária à Justiça Britânica e contrária aosobjetivos da guerra expressos pelas Nações Unidas ${ }^{32}$.

Explicando o quarto ponto acima, o JCCD observou que estava argumentando a favor dos "canadenses nativos ou naturalizados" e não pelos direitos dos inimigos estrangeiros, uma advertência alinhada com as posições do CCJC e de outros grupos de defesa no Canadá. A declaração também apontou que a posição do governo canadense sobre a questão dos direitos estava em descompasso com as políticas governamentais dos Estados Unidos, onde foram garantidos aos nipoamericanos o direito ao voto e mesmo o direito de servir nas Forças Armadas. Poucos nipo-canadenses estavam nas forças militares canadenses, e muitos voluntários foram rejeitados sob argumentos "raciais". O sétimo item da declaração da JCCD também refletia as atitudes do discurso emergente sobre os direitos humanos, quando notava, referindo-se então às Nações Unidas, que era um "lugar comum falar de princípios mais gerais de justiça e decência que devem conquistar a paz que sucederá a guerra”. Subsequentemente, continuou com o aviso que ecoava os sentimentos de outros defensores da causa, para quem "ao lutar contra a opressão fora do país, devemos também estar alertas contra a injustiça em nossa própria casa" ${ }^{33}$.

Uma hora ou outra, a batalha pela igualdade iria chegar às mais altas cortes canadenses. $\mathrm{O}$ caso canadense que acabou encontrando seu caminho até o Privy Council foi produzido a partir de uma decisão coletiva tomada entre os nipo-canadenses e os canadenses de outras origens. O caso não envolveu um requerente; ao contrário, representou os desejos de um grupo de pessoas que queriam que os nipo-canadenses compartilhassem igualmente seus direitos e deveres e que defendiam que não se deveria fazer nenhuma distinção entre os canadenses a partir de pressupostos raciais. Em janeiro de 1946, quando a Suprema Corte do Canadá ouviu o Caso de Referência Nipo-Canadense (Japanese Canadian Reference Case), um certo número de posições foi apresentado. O ponto crítico do argumento era se o governo tinha ou não poderes ilimitados sob a provisão do British North America Act e do War Measures Act ${ }^{34}$ sobre "Paz, Ordem e Bom Governo". Importante notar que ao mesmo tempo o Instituto Gallup de pesquisas anunciou que $62 \%$ dos canadenses agora acreditavam que os nipo-canadenses que eram cidadãos do país deveriam ter a permissão para nele permanecerem. O governo ficou então literalmente atolado por milhares de cartas e telegramas protestando contra a política de deportação. Em particular, as ordens de deportação que pareciam estar fora de sintonia com os princípios da Lei 20, que se tornaria logo o Canadian Citizenship Act (Ato sobre a Cidadania Canadense), apresentado ao Parlamento em 22 de Outubro. Este ato expressou a crença em expansão de que as distinções entre canadenses a partir de argu- 
mentos raciais, ou quaisquer outros, eram muito "não-canadenses" ("un-Canadian”). Ao apresentar o projeto, entretanto, o Secretário de Estado, Paul Martin, assegurou ao Parlamento que sua aprovação não impediria a deportação dos nipo-canadenses ${ }^{35}$.

Em fevereiro de 1946, a corte produziu uma decisão que era, de fato, decididamente ambígua. A corte considerou que o National Emergency Transitional Powers Act (Ato sobre os poderes Provisórios em situação de emergência nacional), dando continuidade aos poderes já conferidos a Ottawa pelo "War Measures Act" (Ato de Medidas de Guerra) para promover a "Paz, ordem e bom governo" da nação, claramente permitia a Ottawa deportar qualquer adulto do sexo masculino que fosse nipo-canadense e que pedisse pela "repatriação", mas que não tivesse anulado sua requisição antes do fim da guerra. Entretanto, a maioria da corte também achou que não havia justificativa suficiente para a deportação das esposas e filhos. Em sua sabedoria, a Suprema Corte deu ao governo federal uma carta branca para prosseguir em sua política de deportação, mas apenas se estivesse disposto a sofrer as consequências políticas que certamente iriam resultar da separação das famílias ${ }^{36}$.

O CCJC decidiu então apelar para o Comitê Judicial do Privy Council em Londres. Brewin apresentou os principais argumentos do CCJC contra a política de deportação, alguns dos quais tinham natureza legal (i.e. a situação de emergência em tempo de guerra não existia mais), mas a maior parte permanecia em um terreno moral: as políticas aviltavam a cidadania canadense e eram racialmente discriminatórias, bem como injustas e desumanas. Ele também ressaltava que muitas das solicitações de repatriação não haviam sido verdadeiramente voluntárias e enfatizava como as políticas violavam os compromissos com os direitos humanos estabelecidos na Carta da ONU. Conjuntamente a esses esforços, o CCJC enviou um memorando a todos os membros do Parlamento e do Senado, acusando o governo de empregar "métodos do Nazismo" e desafiou os parlamentares e senadores a considerar cuidadosamente as ramificações de continuar com a deportação, que, como notava, "realizada sob o argumento racial havia sido definida como um crime contra a humanidade, e os criminosos de guerra da Alemanha e do Japão estão sendo julgados precisamente por este crime" ${ }^{37}$. Até mesmo nos jornais norte-americanos, as políticas do governo canadense estavam atraindo uma atenção desfavorável. Em um editorial do Washington Post, por exemplo, as políticas canadenses eram referidas como:

Uma manifestação odiosa do racialismo canadense [...] Nosso próprio tratamento das pessoas de ascendência japonesa foi, com toda consciência, suficientemente áspero. O tratamento dado pelo Canadá tem sido ainda mais severo[...] O Canadá irá 
refrescar suas próprias importantes tradições de liberdade se der a essas pessoas vítimas de perseguição uma oportunidade de fazer uma escolha genuinamente livre, agora que a histeria da guerra terminou. ${ }^{38}$

Em 2 de dezembro de 1946, o Privy Council decidiu inteiramente em favor de Ottawa, sustentando que o governo tinha o poder até mesmo de deportar as esposas e filhos dos nipo-canadenses nascidos do Canadá. É claro que essa decisão não foi bem vinda pela CCJC, mas não era inesperada. Eles já pretendiam pedir imediatamente ao governo federal para abandonar seus planos no caso de perderem o processo. Apoiados pela mídia e por milhares de canadenses pelo país, em 24 de janeiro de 1947, o governo declarou que sua política de deportação "não era mais necessária”, ainda que sustentasse que o sucesso do programa de reassentamento no Canadá precisava da continuidade das restrições de viagem, bem como das licenças de pesca na costa oeste ${ }^{39}$.

O CCJC congratulou o governo por revogar as "orders-in-council”, mas continuou a batalha para revogar estas restrições, assim como por um acordo justo para os pedidos de indenização pelas propriedades dos nipo-canadenses. Entretanto, estas questões não tinham o mesmo caráter imediato que poderia ter um impacto sobre a opinião pública, como tinha sido o caso da deportação; assim, o CCJC começou a perder a sua posição como o protagonista central dentro da comunidade emergente dos direitos humanos no Canadá. Diminuiu em tamanho, deixando de ser uma ampla coalizão voltada a proteger as liberdades civis, tornando-se um pequeno comitê inteiramente focado sobre as restrições ao direito de propriedade. Em torno do início dos anos 1950, a maior parte dessas questões havia sido resolvida, e o CCJC desmobilizou suas atividades ${ }^{40}$.

\section{CONCLUSÕES}

Antes da Guerra, poucas pessoas no Canadá viam os nipo-canadenses como cidadãos. Mas a década de 1940 precipitou uma reavaliação fundamental dos direitos dos japoneses e de seu lugar na sociedade canadense. De modo semelhante, os nipo-canadenses reconsideraram seu lugar entre seus concidadãos.

As questões do reassentamento, da deportação e das restrições à imigração permitiram aos grupos minoritários do Canadá se darem conta que os problemas encarados por um grupo, especialmente no que diz respeito ao preconceito racial, teria implicações para outras minorias. Na medida em que se aproximava o fim da Segunda Guerra Mundial, marcado pelas vitórias Aliadas, a oposição pública a políticas públicas baseadas na raça, tais como o reassentamento, a expatriação e a exclusão se tornaram mais pronunciadas. Como resultado, uma atmosfera mais capaz de acomodar o pensamento divergente se desenvolveu, 
incluindo aquele das organizações que representavam as minorias. Quando grupos como o Congresso Judeu Canadense, por exemplo, juntou-se a outras organizações para condenar abertamente o tratamento dos nipo-canadenses, isso marcou um importante passo em direção a uma maior cooperação no pós-guerra em outras questões de interesse mútuo.

As organizações nipo-canadenses reconheceram a importância do apoio dos euro-canadenses e a necessidade de cooperar plenamente com estes grupos. A luta canadense para superar as adversidades raciais exigiu um esforço de cooperação entre minorias e não-minorias. Assim, quando o Congresso Judeu Canadense solicitou o apoio da Associação Nacional dos Cidadãos Nipo-Canadenses (NJCCA) para pressionar pela aprovação da legislação sobre as Práticas de Emprego Justo (Fair Employment Practices legislation), o NJCCA prontamente concordou, nas palavras do seu Presidente, George Tanaka, "porque nós sabemos como é sofrer a discriminação"41. E de fato, pouco antes que a NJCCA foi formada, Kinzie Tanaka, exercendo papel de diretor do Nisei Affairs, um jornal nipo-canadense, estava entre os primeiros a incentivar a comunidade nipo-canadense a trabalhar pelo "bem comum", notando que "nós não iremos conseguir nossos fins enquanto não tivermos lutado altruisticamente os combates dos outros por alguns direitos humanos básicos” (ênfase da autora). Os apelos para que os nipo-canadenses não fossem egoístas e trabalhassem pelos direitos dos judeus e afro-canadenses repetiam-se em suas páginas. Muriel Kitagawa, escrevendo em Nisei Affairs sob o pseudônimo de Sue Sada, publicou uma crítica às políticas governamentais que continuavam as restrições do pós-guerra contra os nipocanadenses que se intitulava: “Hoje os japoneses. Amanhã?”. Não era surpreendente, portanto, que o JCCA Nacional também viesse a apoiar as demandas dos canadenses por um "Bill of Rights" e por legislações que estabelecessem práticas de justo emprego (fair employment practices). A declaração submetida ao Parlamento pelo Comitê por uma Carta de Direitos incluía mesmo uma cláusula sublinhando a proibição do exílio de cidadãos canadenses. Esse era, claramente, um reconhecimento das lutas da comunidade nipo-canadense contra a expatriação. Com a última campanha pela legislação por práticas de justo emprego, particularmente em Ontário, comunidades étnicas se deram conta do valor da construção de coalisões ${ }^{42}$. Ainda que o CCJC tenha se desmobilizado em 1951, seus ativistas aprenderam valiosas lições e as aplicaram em outras campanhas. De igual importância é que a linguagem dos direitos humanos, testada pela primeira vez na campanha pelos direitos humanos de pessoas de ascendência japonesa, deixou sua marca no debate.

Também é um aspecto significativo desse episódio o fato de que pessoas de ascendência japonesa foram ativas em sua própria defesa e participaram na 
articulação dos direitos humanos como um conceito importante. Apesar das pressões da comunidade para obedecer as políticas governamentais, alguns nipo-canadenses iniciaram muitos dos primeiros protestos contra as políticas discriminatórias dirigidas contra eles. De fato, muitos tiveram mesmo papéis de liderança dentro da CCJC. No Canadá, as suas dinâmicas - a do movimento dos grupos minoritários e a dos grupos não-minoritários - articularam-se para tornarem-se eficazes, proclamando a natureza cooperativa da comunidade dos direitos humanos que se desenvolvia no Canadá. Mais do que isso, a decisão de organizações de minorias cooperarem integralmente com outros grupos de defesa de direitos no Canadá, particularmente o CCJC, e a evidência que pessoas de ascendência japonesa eram bem-vindas nesses grupos como participantes em relativa igualdade, simbolizaram a natureza do movimento pelos direitos humanos que começava a emergir no Canadá do pós-guerra. Muito antes que o multiculturalismo tivesse se tornado uma política sancionada pelo Estado no Canadá, alguns membros das comunidades nipo-canadenses estavam entres os primeiros a lutar pela participação integral das minorias étnicas e raciais na democracia canadense, lado a lado de seus camaradas anglo-canadenses.

Uma mudança tanto na linguagem quanto no foco, de uma preocupação com a erosão das liberdades britânicas em direção a um interesse nos direitos humanos emergiu lentamente no Canadá dos anos 1940. A discriminação racial recebeu um grau de atenção maior do que tinha antes da Segunda Guerra Mundial. Grupos como o CCJC, ainda que notáveis por seus objetivos, não atuaram como defensores dos direitos de todos no Canadá. A cidadania era um importante fator determinante em seu nível de apoio. Eles eram grupos de interesse que abordavam questões pontuais no âmbito das políticas públicas. A falta de um sistema de proteção aos direitos humanos não foi questionada: esse trabalho seria tarefa de campanhas futuras dos membros da comunidade pelos direitos humanos no Canadá.

\section{NOTAS}

\footnotetext{
2 Henry Wilcoxon (1905-1984) foi um ator britânico, nascido na República Dominicana (nota do tradutor).

${ }^{3}$ Mrs. Miniver (1942). Dirigido por Willian Wyler e produzido pela MGM.

${ }^{4}$ DANIELS, Roger. Asian America: Chinese and Japanese in the United States since 1850. Seattle: University of Washington Press, 1989. P. 4. Esta observação reitera aquela feita em seu trabalho anterior, The Politics of Prejudice: The Anti-Japanese Movement in California and the Struggle for Japanese Exclusion. New York: Atheneum, 1973.

5 É importante notar que este autor usa o termo "encarceramento" ao invés de "internamento" para descrever o tratamento dos nipo-canadenses em tempo de guerra. De fato, apenas 750 nipo-cana-
} 
denses e pessoas de nacionalidade japonesa foram internados no sentido legal da palavra em um campo perto de Angler, Ontario. Os nipo-canadenses restantes da costa oeste da Colúmbia Britânica foram colocados em campos no interior da província através de procedimentos ilegais e foram, portanto, encarcerados.

${ }^{6}$ Para saber mais sobre o debate a respeito da terminologia, ver: DANIELS, Roger. "Words Do Matter: A Note on Inappropriate Terminology and the Incarceration of the Japanese Americans". In: FISET, Louis; NOMURA, Gail M. (ed.). Nikkei in the Pacific Northwest: Japanese Americans and Japanese Canadians in the Twentieth Century. Seattle and London: University of Washington Press, 2005. Cap. 9; Daniels. "The Forced Migration of West Coast Japanese Americans, 1942-1946: A Quantitative Note". In: DANIELS, Roger et al (ed.). Japanese Americans: From Relocation to Redress. P. 72-74; KASHIMA, Tetsuden. Judgment Without Trial: Japanese American Imprisonment during World War II. Seattle: University of Washington Press, 2003. P. 9- 10. Sobre a "a onda de idealismo igualitário" ver, por exemplo: FRAGER, Ruth; PATRIAS, Carmela. “'This Is Our Country, These Are Our Rights': Minorities and the Origins of Ontario's Human Rights Campaigns". Canadian Historical Review, v. 82, n. I, p. 2, March 200I; HOWE, R. Brian. "The Evolution of Human Rights Policy in Ontario". Canadian Journal of Political Science, v. 24, n. 4, 199I, p. 783-802; WALKER, James W. St. G.. "Race," Rights and the Law in the Supreme Court of Canada: Historical Case Studies. Waterloo e Toronto: The Osgoode Society for Canadian Legal History e Wilfrid Laurier University Press, 1997. P. 31 ; LAMBERTSON, Ross. Repression and Resistance: Canadian Human Rights Activists 1930- 1980. Toronto: University of Toronto Press, 2005. Cap. 3.

7 IKEDA, Kaoru. "Slocan Diary". In: OIWA, Keibo (ed.). Stone Voices: Wartime Writings of Japanese Canadian Issei. Montreal: Vehicule Press, 1991. P. 120-121.

${ }^{8}$ Canada, Gazette, P.C. 365, 16 de Janeiro 1942 (27 de Janeiro de 1942); P.C. I 486, 24 de Fevereiro de 1942 (27 de Fevereiro de 1942); "Regulations of Minister of Justice Implementing the Evacuation," 26 de Fevereiro de 1942 (7 de Março de 1942).

9 SCHMEISER, Douglas A. Civil Liberties in Canada. New York: Oxford University Press, I 964. P. 257.

${ }^{10}$ WARD, Peter W. White Canada Forever: Popular Attitudes and Public Policy Toward Orientals in British Columbia. 2nd ed. Montreal, QC: McGill-Queen's University Press, 1990. Cap. 8; ADACHI, Ken. The Enemy That Never Was: A History of the Japanese Canadians. ed. rev. Toronto, ON: McClelland \& Stewart, 199I. Apêndice II, p. 424-427; BANGARTH, Stephanie D. Bangarth, AMackenzie. "King and Japanese Canadians". In: ENGLISH, John; MCLAUGHLIN, Kenneth; LACKENBAUER, P. Whitney (ed.). Mackenzie King: Citizenship and Community. Toronto: Robin Brass Studio Press, 2002; LAC, RG 24, vol. 5195, correspondência secreta, F. J. Mead to Captain H. R. Stewart, 17 de Abril de 1945. Canada, Department of Labour, Two Reports on Japanese Canadians in World War II, 1944/1947, p. 17. Com relação à extensão dos resultados da política de reassentamento com relação ao efeito desejado, Montreal fornece um excelente exemplo. A cidade de Montreal, por volta de 1949 , era povoada por 1300 nipo-canadenses, o que era a maior comunidade japonesa no mundo francófono, de acordo com: ROBINSON, Greg . "Two Other Solitudes': Historical Encounters between Japanese Canadians and French Canadians," 2005. Acesso em: <http://www.discovernikkei.org/wiki/ index.php/Robinson_Two_Solitudes>.

" $\bigcirc$ "Cooperative Commonwealth Federation" foi um partido de esquerda influente no Canadá entre os anos 1930 e 1960. Resultou da união de sociedades cooperativas rurais com sindicatos e tinha tendência socialista. (NT)

${ }^{12}$ Co-operative Committee on Japanese Canadians, Paper, 1943-1951, McMaster University Libraries, Hamilton, Ontario (de agora em diante CCJC-MAC), Edith Fowke, They Made Democracy Work: The Story of the Co-operative Committee on Japanese Canadians (Toronto: s.e., I 95 I).

${ }^{13}$ FOWKE. They Made Democracy Work; LAMBERTSON. Repression and Resistance,.Cap. 3.

14 "Slim Majority of Canadians Favour 'Repatriation' Says Poll," e "Public Opinion on 'Repatriation', " The New Canadian, 8 de Janeiro de 1944; "Cross-country Poll Against Deportation of Citizens," The New Canadian, 26 de Fevereiro de 1944.

${ }^{15}$ UCC, Board of World Missions, Japan Mission, 1880-1971, Caixa 6, pasta \# I36, carta, Howard 
Norman para Rev. Dr. J. Arnup, 10 de Outubro de 1943. Ver também: McMaster University Archives, Co-operative Committee on Japanese Canadians Papers, (CCJC-MAC), fldr \#20, "Declaration of Purpose," FCSO, Vancouver Unit, Canada's Japanese, s.e.

16 UCC, Board of World Missions. Japan Mission, 1880-197I. Caixa 6, pasta \# 136, carta, Howard Norman para Rev. Dr. J. Arnup, 10 October 1943. Ver também McMaster University Archives, Cooperative Committee on Japanese Canadians Papers, (CCJC-MAC), fldr \#20, 'Declaration of Purpose', FCSO, Vancouver Unit, Canada's Japanese, s.d.; Richard Allen, The Social Passion: Religion and Social Reform in Canada, 1914-1928, (Toronto: University of Toronto Press, 1971), p. 16. O movimento do Evangelho Social também se ramificou em outras vertentes distintas do ativismo pelos direitos humanos, como o movimento da pureza social, que enfocava os aspectos morais e sexuais da vida social. Para uma discussão sobre o movimento da pureza social, ver: VALVERDE, Marianna. The Age of Soap, Light, and Water: Moral Reform in English Canada, 1885- 1925. Toronto: McClelland \& Stewart, | 991.

${ }_{17}$ Como citado em: LEE, Carol F. "The Road to Enfranchisement: Chinese and Japanese in British Columbia," BC Studies, n. 30, Verão 1976, p. 52.

${ }^{18}$ UCC, Board of Overseas Missions. Caixa I0, Arquivo \#368, carta, Arnup para Hon. W. P. Mulock, M.P., 12 de Julho de 1944; carta, Arnup para Hon. William Lyon Mackenzie King, M.P., 12 de Julho de 1944; carta, Rev. A. E. Armstrong para J. W. Noseworthy, 12 de Julho de 1944; Armstrong para King, 12 de Junho de 1944; UCC, FCSO, Christian Social Action, "Decisions of the annual conference," Julho-Agosto, 1943; ibid., Rev. John W. Grant, "Disfranchisement Imperils Democracy," Julho-Agosto, 1944. Ênfase da autora.

19 UCC, Board of Overseas Missions. Caixa I0, arquivo \#368, carta, Arnup para Hon. W. P. Mulock, M.P., 12 de Julho de 1944; carta, Arnup para Hon. William Lyon Mackenzie King, M.P., 12 de Julho de 1944; carta, Rev. A. E. Armstrong para J. W. Noseworthy, 12 de Julho de 1944; Armstrong para King, 12 de Junho de 1944; UCC, FCSO, Christian Social Action, "Decisions of the annual conference," Julho-Agosto, 1943; ibid., Rev. John W. Grant, "Disfranchisement Imperils Democracy," Julho-Agosto, 1944.

20 "Order-in-Council" é uma peça legislativa própria do Commonwealth (nota do tradutor).

${ }^{21}$ HARRISON, M. The Social Influence Of The United Church of Canada In British Columbia, 1930- 1948. 1975. M.A. dissertation - University of British Columbia, 1975. P. 186- I89; LaViolette, The Canadian lapanese, p. 196.

${ }^{22}$ De um encontro da Conferência da United Church da Colúmbia Britânica em maio de 1944, como citado em: HEMMINGS. 'The Church and the Japanese Canadians'. P. I08- 109.

${ }^{23}$ RG25, Vol. 3005, Série G-2, arquivo 3464-B-40, carta, G. Glazebrook, Under Sec'y of State for External Affairs para F. Charpentier, Chief Sensor of Publications, Dep't of National War Services, 18 de Agosto de 1944. Ver também a carta, F. Charpentier para T. A. Stone, Secy, Dept of Ex Affairs, 19 de Janeiro de 1944.

${ }^{24}$ NAC, RG 25, vol. 2798, file 773-B-1-40, parte 3, carta, Black para King, 29 de Maio de 1944

${ }^{25}$ CCJC-MAC, fldr \# 12, 'A Record of the Work of the Cooperative Committee on Japanese Canadians', p. II.

${ }^{26}$ CCJC-MAC, fldr \#20, 'Emergency Bulletin of Japanese-Canadians,' special bulletin to all youth Christian groups from the Student Christian Movement of Canada, 15 October 1945. Ênfase da autora. Os membros eram encorajados a enviar telegramas ou escrever ao Primeiro Ministro King, ao Ministro do Trabalho, ao Sub-Secretário de Estado, aos governantes provinciais e a estudar a questão do internamento e disseminar as informações através das universidades e da ação local. O SCM também aconselhava os comitês associados a aproximar-se das igrejas locais, clubes universitários, clubes de serviço e sindicatos para solicitar-lhes que abraçassem "a causa" e fizessem que sua voz fosse ouvida através da escrita de cartas para os jornais dos campi e da cidade.

27 CCJC-MAC, fldr \# I0, CCJC news bulletin \#2, 24 de Janeiro de 1946.

${ }^{28}$ CCJC-MAC, file \# I2, Fowke, 'They Made Democracy Work," p.22.

29 MACINNIS, Grace. "Wanted: A Country," Canadian Forum, Junho de 1942; Grace e Angus Maclnnis, "Oriental Canadians - Outcasts or Citizens?"; MACINNIS, Angus, "Should We Send the Japs Back? 
- No," Maclean's, I de Dez 1943, p. 12, 37-38; Werner Cohn, "The Persecution of Japanese Canadians and the Political Left in British Columbia, Dez de 1941 - Março 1942, em BC Studies, n. 68, (Winter 1985-86): 3-22.

${ }_{30}$ NAC, MG 28, Series I, I4, v. I, minutas, Cooperative Committee on Japanese-Canadian Arrivals in Toronto, 8 de Junho de 1943, p. 2; NAC, MG 28, Série I, 14, v.2, "A Record of the Work of the Cooperative Committee on Japanese Canadians", p. I. Este documento também pode ser encontrado nos Arquivos da McMaster University, Co-operative Committee on Japanese Canadians Papers (CCJC-MAC), arquivo \# 12; Jarnail Singh, "Wartime Toronto and Japanese Canadians," Polyphony, Verão 1984: 199-200. O texto deste artigo foi baseado em uma entrevista com George Tanaka. Ad Hoc Committee for "Japanese Canadian Redress: The Toronto Story," Japanese Canadian Redress: The Toronto Story, (Toronto: Hpf Press, 2000), cap. I, 'The Roots of Our Struggle.

3! Singh. "Wartime Toronto and Japanese Canadians," p. 2-3.

32 NAC, MG 28 V7, Vol. I, file \#23, JCCD Brief in the matter of the War Services Elector's Bill (\# I 35 de 1944) Seção 5 Relacionando certa Ememnda à Secção 14 ss. 2 do Dominion Elections Act (Ato de Eleições do Domínio), 1938 e sobre a questão da Destituição de Direitos dos Súditos Britânicos e dos Cidadãos Canadenses no Canadá, 24 de Junho de 1944, p. 2.

${ }_{33}$ lbid., p. 6-10.

34 O "British North America Act", promulgado pelo Parlamento britânico em 1867 estabeleceu a federação das províncias canadenses, dotou-as de uma constituição e de poderes governativos e estabeleceu a relação entre as províncias e a federação, sendo reconhecido como o ato de independência do Canadá. O "War Measures Act" de 1914 deu ao governo amplos poderes em tempo de guerra, invasão ou insurreição. (N. T.)

${ }^{35}$ Para numerosas cartas e petições protestando contra as ações do governo, ver: LAC, RG 2 ser. G2, v. 3554, arquivo 773-B-1-40, pt. 4. Sobre a Lei 20, ver: Canada, House of Commons, Debates, 22 de Outubro de 1945, p. 1335 (primeira leitura). Os comentário de Martin foram feitos durante a segunda leitura da lei, em 6 de abril de 1946. O Canadian Citizenship Act (Ato da Cidadania Canadense) foi aprovado em 1946 e entrou em vigor a partir de $1^{\circ}$ de Janeiro de 1947 . O Primeiro Ministro William Lyon Mackenzie King teve a distinção de ser o primeiro cidadão canadense.

${ }^{36}$ In the Matter of a Reference as to the Validity of Orders in Council of the 15 th Day of December, 1945 (P.C. 7355, 7356 and 7357), in Relation to Persons of the Japanese Race (1946) Supreme Court Reports 248.

${ }^{37}$ LAC, MG 28, v. I , arquivo I, minutas, 22 de Janeiro e 22 de Março de 1946 e Bolteim de Notícias do CCJC, 7 e 14 de Setembro de 1946; LAC, MG 32 C26, v. 3, arquivo 3-3, Declaração, "To the honourable Members of Senate and the House of Commons," 1946.

${ }^{38}$ Editorial, "Halt Exile of Japs, US advice to Canada," Washington Post, I I de Junho de 1945.

39 FOWKE. They Made Democracy Work, p. 23. Os títulos oficiais do apelo a ao Privy Council são Cooperative Committee on Japanese Canadians v. A.G. Canada (1947) A.C. 87, I DLR 577.

${ }^{40}$ FOWKE. They Made Democracy Work, p. 23-25, 32; MLAC, MG 28, vol. I, arquivo I, "Report of the Sub-committee on Restrictions and Property Losses," 26 de Outubro de 1946; CCJC-MAC, pasta I3, "Statement to Claimants RE Origin, Nature and Work of the Co-operative Committee on Japanese Canadians," Abril de 1950, p. 3.

${ }^{41}$ LAC, MG 3 I F8, Minoru Takada Papers, 'report of 2nd National JCCA conference,' s.a., s.d. (1947?).

${ }^{42}$ LAC, MG 28 V7, rolo CI2830, artigo, George Tanaka, 'For the Protection of Human Rights,' 26 January 1950; Nisei Affairs, vol. 2, n. I, Janeiro de 1947, v. 2, n. 3, Abril de 1947, v. 2, n. 4, Junho de 1947; Kitagawa, This is My Own, pp. 236-24I; Lambertson, Repression and Resistance, cap. 5 e 8; James W. St. G. Walker, "The 'Jewish' Phase in the Movement for Racial Equality in Canada," Canadian Ethnic Studies, v. 34, no. I (2004): I-24. 